\title{
THE CHRONOLOGY OF THE LATE BRONZE (LB)-IRON AGE (IA) TRANSITION IN THE SOUTHERN LEVANT: A RESPONSE TO FINKELSTEIN'S CRITIQUE
}

\author{
Elisabetta Boaretto ${ }^{1 *} \cdot$ Yotam Asscher $^{2} \cdot$ Louise A Hitchcock $^{3} \bullet$ Gunnar Lehmann $^{4}$ • \\ Aren M Maeir ${ }^{5}$ Steve Weiner ${ }^{6}$ \\ ${ }^{1}$ D-REAMS Radiocarbon Dating Laboratory, Weizmann Institute of Science, Rehovot 7610001, Israel. \\ ${ }^{2}$ Department of Geosciences, University of Padova, Padova 35131, Italy. \\ ${ }^{3}$ Classics and Archaeology, University of Melbourne, Parkville 3010, Victoria, Australia. \\ ${ }^{4}$ Department of Bible, Archaeology and Ancient Near Eastern Studies, Ben-Gurion University of the Negev, \\ Beer-Sheva 84105, Israel. \\ ${ }^{5}$ The Ackerman Family Bar-Ilan University Expedition to Gath, the Martin (Szusz) Department of Land of Israel \\ Studies and Archaeology, Bar-Ilan University, Ramat Gan 52900, Israel. \\ ${ }^{6}$ Kimmel Center for Archaeological Science, Weizmann Institute of Science, Rehovot 7610001, Israel.
}

\begin{abstract}
The question under discussion is whether the dates of the Late Bronze (LBIIB)-LBIII (Iron IA) transitions in three sites in the southern Levant, namely Megiddo, Tell es-Safi/Gath and Qubur el-Walaydah occur at the same time, as has been proposed by Israel Finkelstein in his article in 2016 in Egypt and Levant. Here we respond to Finkelstein's comments. We add some new data, clarify the issues that were raised, and conclude that the Late Bronze (LBIIB)-LBIII (Iron IA) transitions occurred at different times in northern and southern Israel.
\end{abstract}

KEYWORDS: microarchaeology, radiocarbon context, southern Levant, transition dating.

\section{INTRODUCTION AND DISCUSSION}

The Late Bronze Age to Iron Age transition in the southern Levant includes the appearance of a new material culture that is reminiscent of the Aegean world. The distribution of early styles of Aegean-like pottery, produced locally in the southern Levant, is confined to the coastal areas of Canaan, making synchronization with other sites even in this relatively small region, difficult. Recently, three high-resolution radiocarbon $\left({ }^{14} \mathrm{C}\right)$ dating studies have been published that provide a chronological framework for synchronizing ceramic phases across this transition. These studies have led to a discussion of the reliability of the results in terms of archaeological contexts and their associations with the cultural materials.

The specific question under discussion is whether the dates of the Late Bronze (LBIIB)-LBIII (Iron IA) transitions in the 3 sites in the southern Levant, namely Megiddo, Tell es-Safi/Gath) and Qubur el-Walaydah occur at the same time, as has been proposed by Finkelstein (2016) or at different times? Figure 1 summarizes the $1 \sigma$ ranges of the transition models in each of these three sites based on Toffolo et al. (2014) for Megiddo, Asscher et al. (2015a) for Tell es-Safi/ Gath and Asscher et al. (2015b) for Qubur el-Walaydah. Clearly the transition dates for Megiddo as published are later than the transition dates for the other two sites. The archaeological significance of this question is that this transition reflects the appearance of new elements of the material culture in addition to the existing material culture that continues through the transition. These new elements are assumed to have been produced by the arrival of the "Sea Peoples" in Tell es-Safi/Gath and Qubur el-Walaydah (Philistia), which influenced the material culture through cultural exchange in Megiddo (Northern Canaan). Finkelstein questions whether the quality of the archaeological records at Tell es-Safi/Gath and Qubur el-Walaydah are good enough to draw this conclusion. The focus of Finkelstein's criticism is on the sites of Qubur el-Walaydah and Tell es-Safi/Gath, but the discussion must obviously also include Megiddo. We also note that the dating of all three sites was carried out by Boaretto's team, and at each site the directors of the excavation were involved in all field related aspects, and coauthored the respective publications.

\footnotetext{
*Corresponding author. Email: elisabetta.boaretto@weizmann.ac.il.
} 


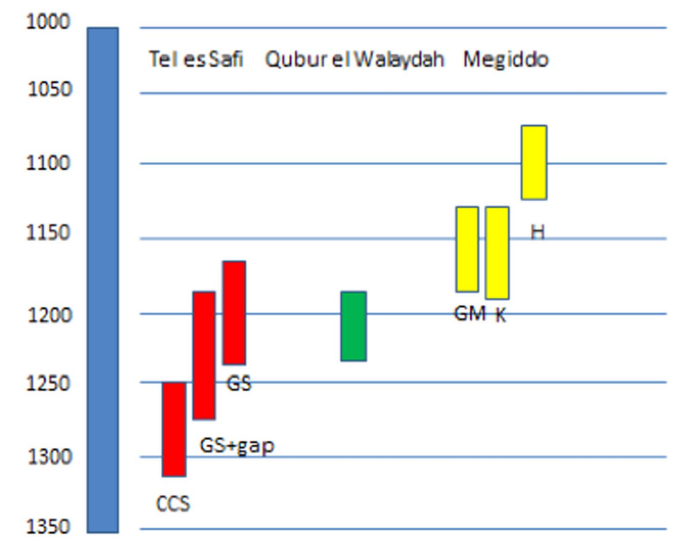

Figure 1 Different Bayesian models for the transition date ranges of the Late Bronze (LBIIB)-LBIII (Iron IA) in the three different sites under discussion. Vertical bars represent the calibrated time range BC of individual dates (for $\pm 1 \sigma, 68.2 \%$ probability). For the Tell es-Safi/Gath the three bars are for CCS $=$ combined cultural-stratigraphy model; GS + gap = geostratigraphy + gap model; GS = geostratigraphy model. All these models are presented in Asscher et al. (2015a). For the Megiddo site, the three bars are for $\mathrm{GM}=$ general model; $\mathrm{K}=$ area $\mathrm{K}$ only; $\mathrm{H}=$ area $\mathrm{H}$ only. All these models and a discussion of these results are presented in Toffolo et al. (2014).

We first note that the two papers (Asscher et al. 2015a, 2015b) on Qubur el-Walaydah and Tell es-Safi/Gath include all the relevant details related not only to the ${ }^{14} \mathrm{C}$ dating, but also descriptions of the pottery in relation to the samples dated, so that others can either form their own opinions or criticize the methods used. We note however that comparable data were not published for the dating of this transition for the site of Megiddo. We therefore appreciate the fact that Finkelstein exploited the detailed data from Qubur el-Walaydah and Tell es-Safi/Gath to criticize the method used, but regret the fact that he did not maintain a strictly scientific approach and focus only on the data. This is strikingly revealed in his almost final statement, after reviewing the data, where he states that, "Placing the appearance of the monochrome... in the 13th century BC gives it an impossibly long period of over 150 years!" Is it really 150 years (see Figure 1 for the published details and discussion below) and how does he know that 150 years is impossibly long? This reflects a preconception that is unconnected to the data. A similar preconception is the expectation that sites in the same general area should give similar resultsarchaeology is a lot more complicated than that. Several examples of this complexity can be given: (1) there is a lack of any cultural interaction between the neighboring Egyptian and Philistine sites, Tel Mor V and Ashdod XIII, both dated to the beginning of the first half of the 12th century BC (Killebrew 2013); (2) another example is that there is a 60-yr difference in the Modeled LB-IA transition dates between two areas within the same site (Megiddo); (3) a third example is that the final LB destruction at Hazor dates to about $1250 \mathrm{BC}$ and the final LB destruction at Megiddo dates to about $1100 \mathrm{BC}$, even though both sites are in the same general geographical area. Thus, the assumption on which Finkelstein arrives at the conclusion that one of our results must be wrong is hard to accept.

Without entering yet into a detailed discussion of the quality of these data, ${ }^{14} \mathrm{C}$ results clearly show that the transition at Megiddo is later than at the other two sites (Figure 1). Finkelstein's choice of a 150-yr difference is misleading. In fact, upon inspection of Figure 1, and when using the mean values for each transition model, the difference could range from 50 to $175 \mathrm{yr}$. Understanding the options requires understanding the details, not only at Tell es-Safi/Gath and Qubur el-Walaydah, but also the difference between Areas H and K at Megiddo. 
Finkelstein lists five components that are essential for defining a chronological sequence. Indeed, stratigraphy, exposure, samples, ceramic typology, and continuity are important. Finkelstein's definition of what constitutes good stratigraphy is narrow. Stratigraphy, in our opinion, is all about a sequence of deposits, which includes both the artifacts and features (floors, hearths, ovens, etc.) as well as the sedimentary matrix in which they are present. Floors are very difficult to identify, let alone being sure that the material culture remains are uniquely associated with one dateable floor. Exposure and continuity are closely related, in that continuity cannot be established without extensive exposure. In our experience there are very few examples of a stratigraphic layer that is continuous throughout a fairly extensive area of a site. And yes, ceramic typology of large assemblages is important. However, there are situations where the stratigraphic deposit is identifiable by other means, and even a limited ceramic assemblage is informative. The bottom line is that every site has its strengths and weaknesses, and the challenge is to produce data reliable enough to be interpreted.

\section{Tell es-Safi/Gath}

Stratum A6 is the key to understanding the stratigraphy of Area A, the core area for the radiocarbon dating. The sediments in Stratum A6 have very distinctive properties: phytolithrich, large amounts of charred debris, and a fine grained texture and grey color. All these properties can be identified in the field and/or by analysis. Our understanding of the mode of formation of Stratum A6 is that this is a deposit of ash produced from the burning of animal dung. This deposit is in a heap or pile and not in a pit. Stratum A6 varies in thickness - thinning to the north of Area A. And most importantly, it covers the entire area and underlies all the later Iron Age architecture. It is therefore an ideal stratigraphic deposit. Furthermore, the ${ }^{14} \mathrm{C}$ dates are the same at the top, middle, and base of the layer, and therefore it makes no difference whether the dated charred remains are in clusters or not. The dates span a relatively short period once they are modeled, namely less than 100 years (Asscher et al. 2015a). Stratum A6 is thus a well-defined marker horizon, which in many respects anchors the local stratigraphy; everything above is younger and everything below is older. The layer is continuous, is exposed over a large area, and is not a pit, as Finkelstein assumed. Thus, much of his criticism of the Area A stratigraphy at Tell es-Safi/Gath is not well-founded.

In response to Finkelstein's criticism (2016), we examined much more pottery from baskets collected from Stratum A6 in Square 90C, where this stratum is thickest. Asscher et al. (2015a) only reported the pottery in close association with the materials used for dating (2015a), to avoid the influence of heterogeneity in assemblages at different locations in the stratum that stretches over $50 \mathrm{~m}^{2}$. In this reexamination, we found that Iron I pottery is present throughout Stratum A6, and there is a significant tendency for having more LB material towards the base and more Iron I material towards the top. Most significantly, we identified Myc IIIC sherds, as well as an almost complete restorable Myc IIIC bowl in this stratum (Figures 2 A, B, C). Based on these observations of material culture, Stratum A6 is clearly an early Iron I phase. As this stratum is stratified, we cannot exclude the possibility based on material culture alone that the base of the stratum is LB. However as the whole stratum was deposited in less than 100 years (based on the ${ }^{14} \mathrm{C}$ determinations), even if the transition occurred within the base of the stratum, this would not move the boundary by more than 20 or $30 \mathrm{yr}$. From this we conclude that the results presented by Asscher et al. (2015a) regarding Stratum A6 do indeed document the date immediately after the LB/Iron Age transition at Tell es-Safi/Gath.

Area $\mathrm{A}$ at Tell es-Safi/Gath has a Late Bronze-early Iron Age stratigraphy that is condensed into less than $2 \mathrm{~m}$ thick on the south, but which is thicker on the north. There is a well-defined 


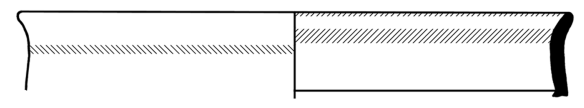

1

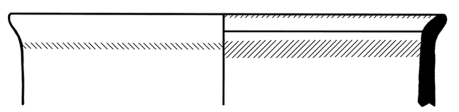

3

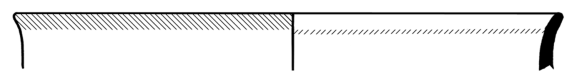

2

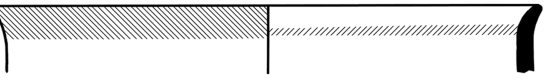

4
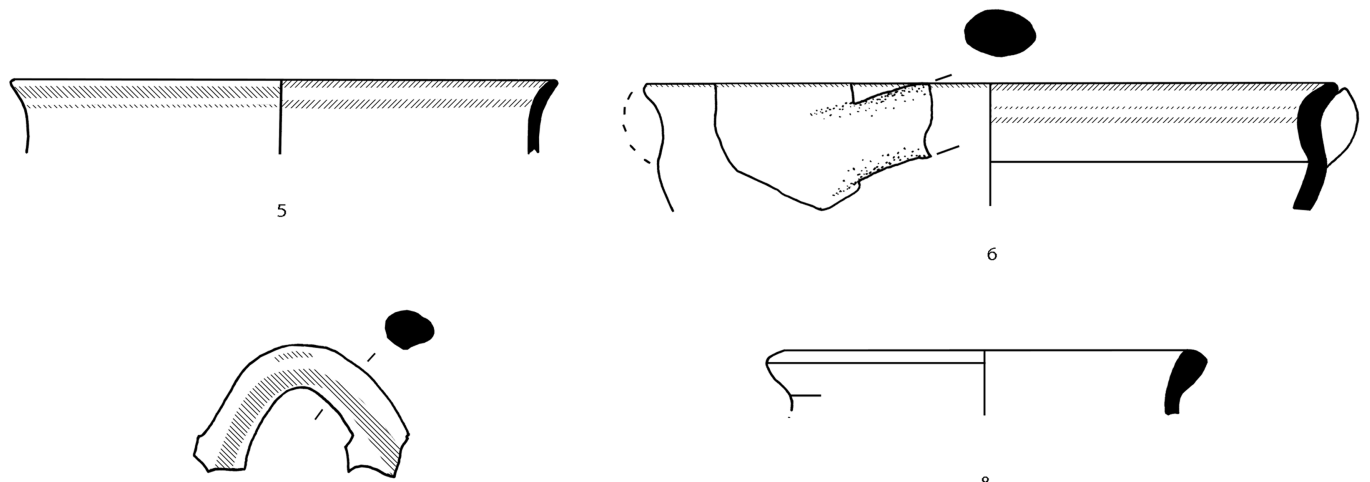

8

7
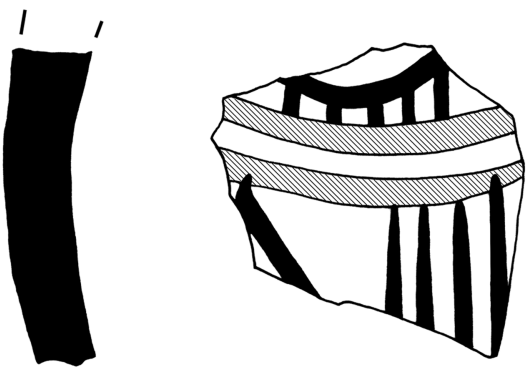

11

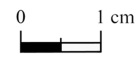

9

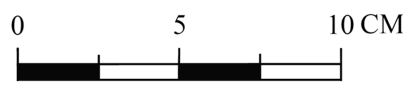

Figure 2A Selected early Iron Age pottery from Tell es-Safi/Gath, Area A, Stratum 6, Locus 142202. 1-7: Philistine 1 (Myc IIIC) vessels; 8: Early Iron Age Aegean-style cooking jug; 9: Philistine 2 (Bichrome) decorated sherd.

sequence of walls of various phases in the Iron Age above Stratum A6. Missing in the Iron Age are continuous layers from different periods of time. We therefore used a different strategy and focused on dating specific locations where we could show that the material dated was charred at that location (in situ context), and each location could be related to a particular wall whose phase was known, and/or characteristic pottery. Below Stratum A6 we identified a thin layer from the Late Bronze, also with charred materials from proven primary contexts. This stratum was underlain by Early Bronze deposits, and therefore there was little opportunity for defining 

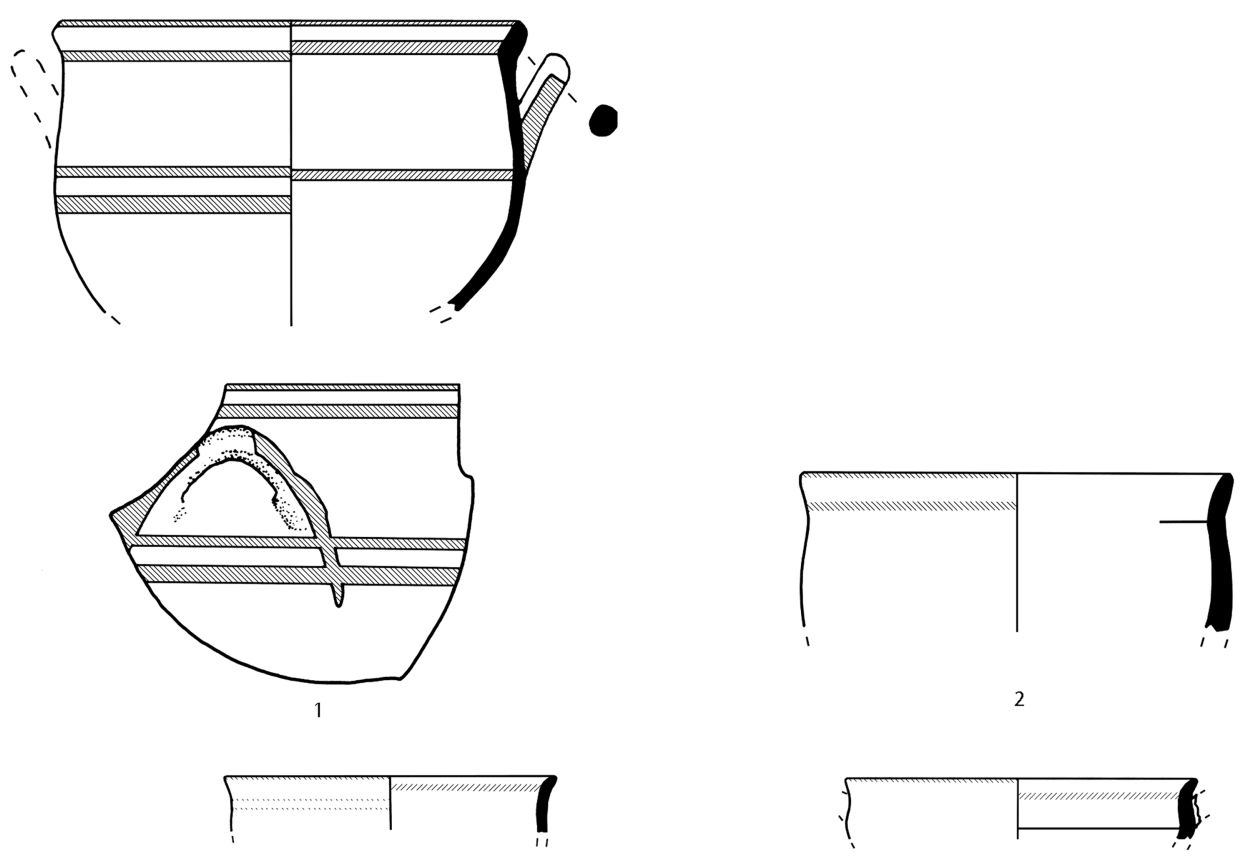

4
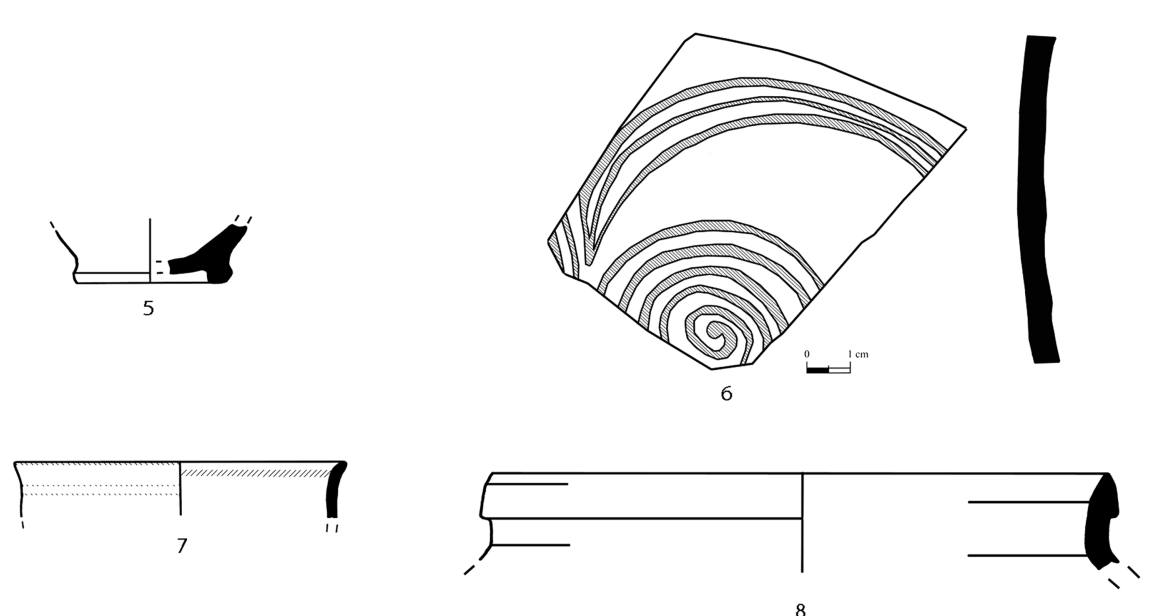

8

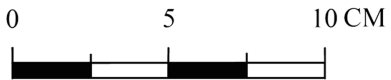

Figure 2B Selected early Iron Age pottery from Tell es-Safi/Gath, Area A, Stratum 6, Locus 142203. 1-7: Philistine 1 (Myc IIIC) vessels; 8: LB/Iron I "Canaanite" cooking pot.

stratigraphy within the LB. We think that the approach used to define and date the stratigraphy is robust, and of course more challenging than at Megiddo, where the rate of sedimentation is much higher, resulting in significantly thicker layers. What we show in our study of Tell es-Safi/ Gath is that you need to adapt your strategy for determining a chrono-stratigraphic sequence to the parameters that the site presents, and exploit the site's strengths and be aware of the weaknesses. 


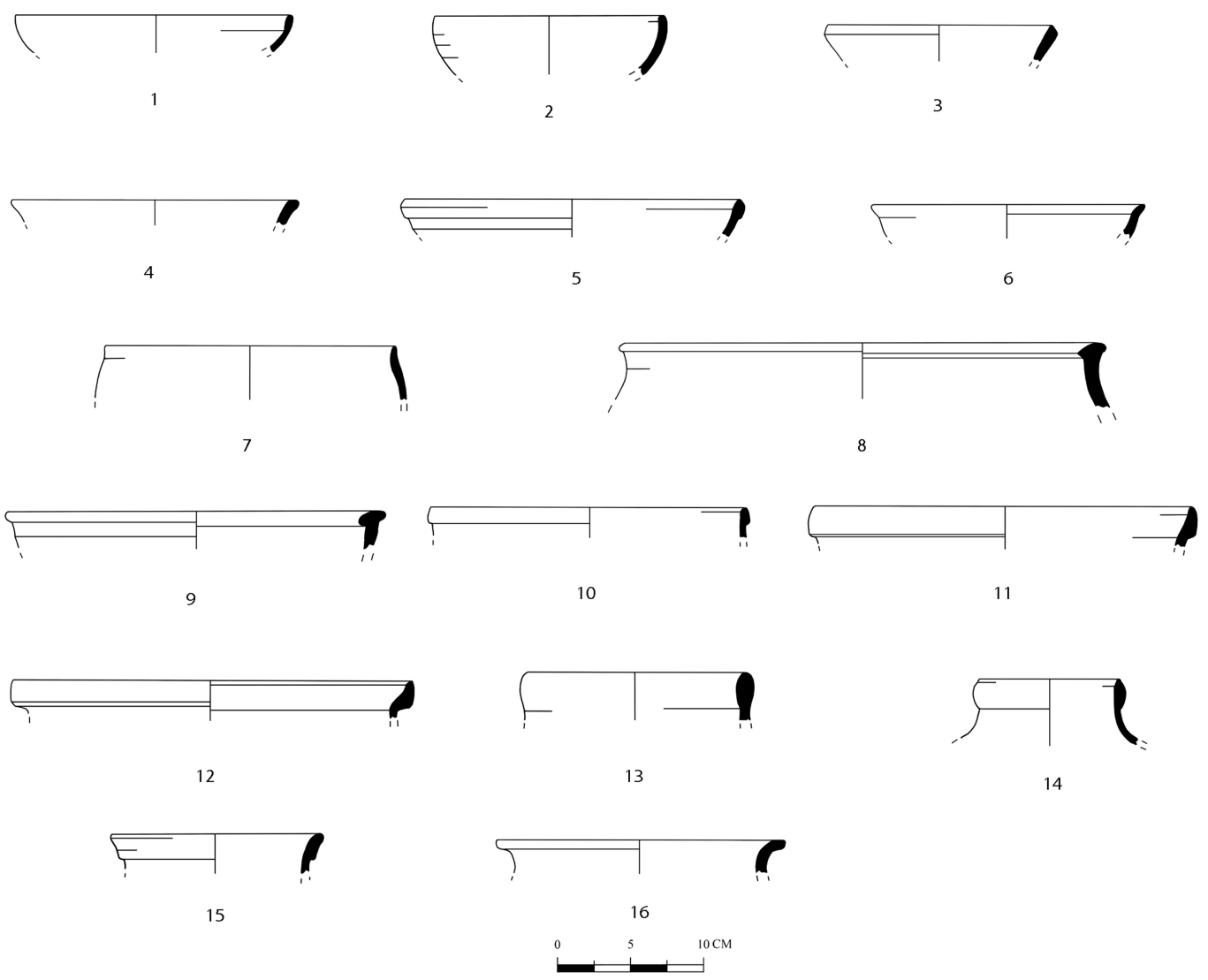

Figure 2C Selected Late Bronze Age pottery from Tell es-Safi/Gath, Area A, Stratum 6, bottom, Locus A15AW02; 1-16: local "Canaanite" pottery.

Finkelstein claims that without the input from Area F where Monochrome ceramics are present (Toffolo et al. 2012), there is no model. We dispute this assertion by the finding of Myc IIIC pottery in Stratum A6 in Area A. Furthermore, each of the three models presented by Asscher et al. has its strengths and weaknesses. The general model (that combines all the areas even though they are physically disconnected) introduces the bichrome and monochrome in the same model, but suffers from the disconnection and the reliance on a single floor analysis, which is known to be problematic (Asscher et al. 2015a). The strength of the geostratigraphic model based only on Area A is that the stratigraphic relations are well defined (mainly because of Stratum A6), but lacks the clean phase of Myc IIIC as in Stratum A6. Note that independent of what Finkelstein considers important, all these models are older than the Megiddo transition, and significantly as more information (for example a gap) was introduced into the model, the trend was towards older transition dates. So it is highly unlikely that the transition dates in Tell es-Safi/Gath are actually younger, or contemporaneous with Megiddo

In Area A, the exposure of Stratum A6 and all the layers from the Iron Age above Stratum 6 is extensive (in contradiction to the statement that "much of what is described... comes from soundings"(Finkelstein 2016:278). Indeed the soundings do expose the thin layer of Late Bronze just below Stratum A6. Even though the exposure was limited, the material that was dated did originate from primary, in-situ contexts, and as this layer is underlain by Early Bronze 
deposits, there is little chance of the dates being "contaminated" by older material without being aware of this.

We conclude that in the Tell es-Safi/Gath study the stratigraphy is based on sherds, characteristic sedimentary layers and architecture feature and therefore, Finkelstein's conclusion that "there is no model - clear and simple" is incorrect. There is a well-substantiated model, now supported even more strongly by the reported ceramic assemblages in Stratum A6, and the transition date is early.

\section{Qubur el-Walaydah}

One of Finkelstein's major criticisms is that some or all of the dated samples were redeposited and therefore do not date the age of the stratum in which they were found. If correct, this is certainly a serious problem. We disagree with this conclusion for the following reasons.

We believe that Finkelstein misunderstood the caption of Table 2 in Asscher et al. (2015b) as meaning that single seeds were found and dated, as opposed to clusters. In fact, a single seed from a cluster of seeds was dated. The presence of clusters is generally inconsistent with redeposition.

We went to great lengths using macro- and microarchaeological techniques to show that the charring process that produced the dated material occurred at the location where the seeds were found. This was the case for both the LB and IA samples. For each sample dated, we provided the evidence for this conclusion. The samples of Square D106 contained dung spherulites, as well as ash and phytoliths. These were very thin and uniformly thick layers, showing neither bioturbation nor local thickening or compositional variations that could be consistent with redeposition. We think that these observations are consistent with primary deposition. We also note that the ${ }^{14} \mathrm{C}$ dates from this sequence become progressively younger from bottom to top, which is unlikely to occur if materials of different ages were brought from other locations.

The number of diagnostic sherds from the sounding in Square D106 was small, but consistent in its date to the Late Bronze Age. Downplaying the significance of the samples because of the limited number of pottery is misleading. Table 2 in Asscher et al. (2015b) lists only the number of diagnostics from the particular baskets of the samples, while the other baskets of the relevant loci contained additional material. Furthermore, all the ceramics (Figure 3 QW1:1-4) date to Late Bronze Age IIB-III and there are no intrusions. It is difficult to distinguish morphologically the local pottery types of the Late Bronze Age IIB from those of the Late Bronze Age III.

The loci in Square B104, Stratum 1-5e and 1-5d, were undisturbed. The pottery dates to Late Bronze Age IIB-III (Figure 3 QW1:6-16). The Stratum 1-5d assemblage included a sherd from a Simple-Style stirrup jar (Figure 3 QW1:16).

Dating the pit (Square C102) is a case in which samples were charred in-situ. However, since it is a pit, Finkelstein concluded the sediments and the pottery do not reflect the charring activity. It is important to note that black lenses were continuously accumulated, resulting in 10 episodes of burnt materials, and that the pottery were collected from the charred lenses and the surrounding sediments. All the pottery, including the charred pottery, was dated to the Iron I (Figure 4 QW2:1-9). This was clearly not a pit that was dug and then filled in one event. In fact the ${ }^{14} \mathrm{C}$ dates show that the pit was filled over a period of years up to several decades. It is more likely that the pit in Square C102 was dug and then exposed to several episodes of refilling and repeated burning over a longer period of time. The pit in fact represents a location that 


\section{DS_5}

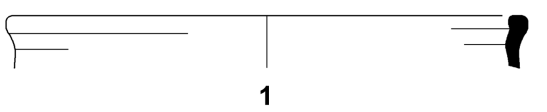

DS_1

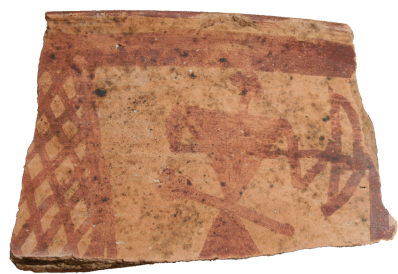

4

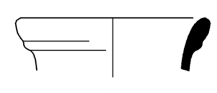

2

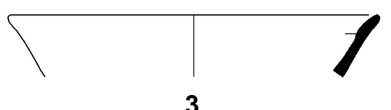

3

Stratum 1-6

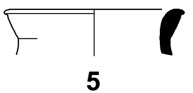

\section{Stratum 1-5e}

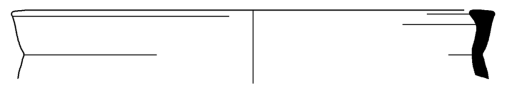

6

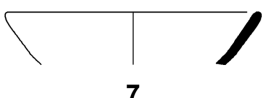

7

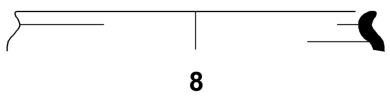

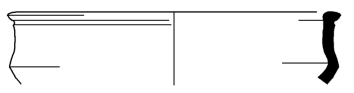

9

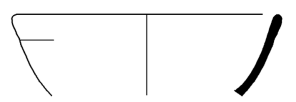

10

\section{Stratum 1-5d}

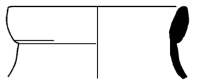

11

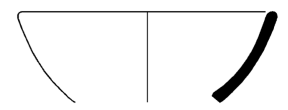

14

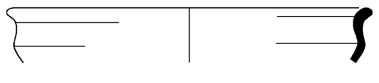

12

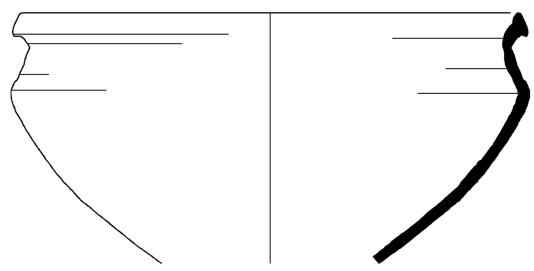

15

0

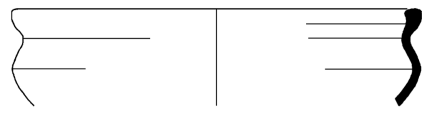

13

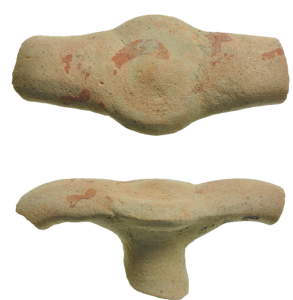

16

Figure 3 Qubur el-Walaydah pottery from loci in square B104, Stratum 1-5e and 1-5d. Different periods were identified; see text for explanation. The ceramics (Fig. QW1:1-4) date to Late Bronze Age IIB-III. Pottery samples QW1:6-16 are from Late Bronze Age IIB-III. In Stratum 1-5d the sherd from a Simple-Style stirrup jar, QW1:16, is shown.

contained in-situ charred ceramics and organic materials and provides reliable evidence for dating with charring processes that are directly linked to ceramic assemblages. We hold that these observations are consistent with primary depositions in the pit. Here too, the ${ }^{14} \mathrm{C}$ dates from this sequence get progressively younger from bottom to top, which is, as in Square D106, unlikely to occur if materials of different ages were brought from other locations. 
Pit 11.015 (1-4_10)

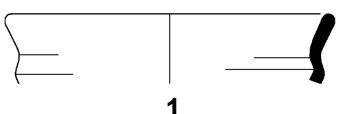

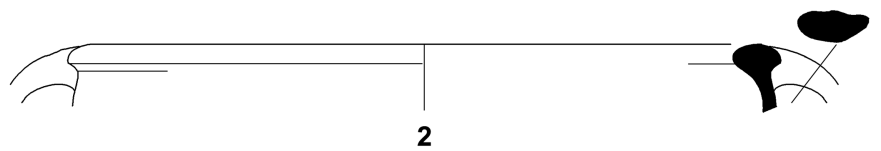

Pit 11.015 (1-4_9) Pit 11.015 (1-4_7 and 8)

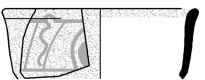

3

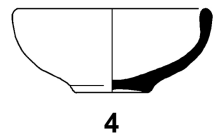

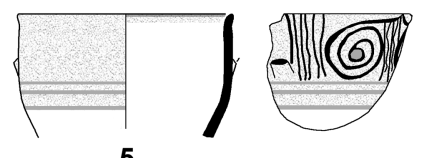

5

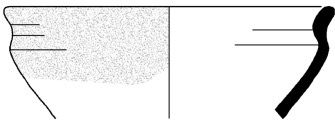

8

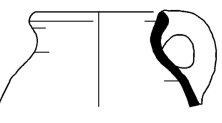

9

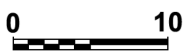

Figure 4 Qubur el-Walaydah pottery from the Iron Age pit in square C102. Pottery finds, QW2:1-9, are all from Iron I.

Finkelstein raised the question whether the accumulations in Squares D106 and B104 are related to architectural elements and floors, and to each other. As we stated in Asscher et al. (2015b), the samples in Square D106 are beneath the building of Stratum 1-5. As the samples were recovered from two different squares, they are physically not under those from Square B104. However, the walls and floor levels of the large building of Stratum 1-5 extended over all the squares from which samples were retrieved. The samples from Square B104 are related to the walls and the floors of the building mentioned. As the samples of Square D106 come from a sounding under the building of Stratum 1-5, they are not related to the building or any other architectural feature. They are however from surfaces located under the floors of the building. Contrary to Finkelstein's assumptions, the exposure of Square D106 might be limited, but the surfaces are clearly defined.

Finkelstein refers to the modeling of the data from Qubur el-Walaydah as "manipulation". The opposite is true. The model clearly presents all the options and in particular defines all the assumptions based on missing data such as gaps, and the agreement of all the chronological assumptions such as the "Low, Middle and High" Philistines chronologies with the data.

\section{Megiddo}

Toffolo et al. (2014) published the ${ }^{14} \mathrm{C}$ dates for Megiddo that include the Bronze to Iron Age transition. The archaeological input reported in this paper does not include the detailed inventory of indicative ceramics for the locations from which material was dated. Table 1 in Toffolo et al. (2014) does refer to the ceramics for each level, but the references given are from publications that preceded the dating or were not published at the time. Thus, information for Megiddo, comparable in detail to that supplied for Tell es-Safi and Qubur el-Walaydah, was not presented (and therefore, cannot be criticized). 
Toffolo et al. report that the Bayesian modeling of Areas $\mathrm{H}$ and $\mathrm{K}$ result in transition dates with a difference of about $50 \mathrm{yr}$. Finkelstein refers to this 50 -yr difference as a "slight difference". This difference is, however, clearly supported by the ${ }^{14} \mathrm{C}$ results. Toffolo et al. (2014) did not claim that this represented a difference in material culture produced at the same site, but Finkelstein re-examined the relevant pottery and concludes that Level H12 probably started during the lifetime of Level K6. This could be an indication that the General Model of Toffolo et al. (2014) is the most appropriate. If so, the transition date of Megiddo is about 50-100 yr after Qubur el-Walaydah and Tell es-Safi/Gath.

\section{THE TAKE-HOME LESSONS}

1. Dateable samples should only be from primary contexts that provide an absolute date for the layer/feature from which the samples were derived. This date will then be the base for all the other components of the layer/feature including the material culture.

2. In order for others to evaluate to what extent each date complies with this condition, all the relevant data associated with the material dated need to be published, including the numbers and interpretations of the indicative pottery sherds, the relevant data on ${ }^{14} \mathrm{C}$ dating (e.g. quality criteria for sample material, counting statistics) and not less important, the evidence that the context being dated is a primary context. No data, including any perceived aberrant ${ }^{14} \mathrm{C}$ dates or potsherds, can be left out.

3. The details of the Bayesian modeling need to be reported, including the rationale for using various parameters.

When all the data are reported in this manner, it will be possible to both evaluate strengths and weaknesses of each site, and compare sites in order to obtain a regional picture.

\section{FINAL COMMENT}

Dating transitions should be approached without preconceived notions about when the transition took place and whether the transition was contemporaneous at different sites, or even within one site. The data need to "speak" for themselves, and the relevant conclusions should be drawn from the data. We are of the opinion that the studies carried out at Tell esSafi/Gath and Qubur el-Walaydah provide the data necessary for carrying out such meaningful discussions, and Finkelstein has indeed used the details to evaluate the output. Hopefully, these two studies set the stage for how future studies will be published and how past studies can be evaluated. We anticipate such an approach will bring us a lot closer to really knowing when the "Sea Peoples" arrived in the southern Levant, when and in what sequence did the Philistine culture appear (in general and at different sites), and of course, document the timing of other vents in the archaeological record. Meanwhile, we stand by our conclusions that the Philistine material culture at Tell es-Safi/Gath and Qubur elWalaydah appeared prior to the appearance of analogous materials at Megiddo. We strongly believe that the processes involved in the appearance, development and spread of the Philistine culture were of a complex and drawn out nature (e.g. Maeir and Hitchcock 2017), and cannot be assumed to be related solely to specific and short term historical events (such as a confrontation between Rameses III and the Sea Peoples as supposedly reflected in the Medinet Habu Temple reliefs). 


\section{REFERENCES}

Asscher Y, Cabanes D, Hitchcock LA, Maeir AM, Weiner S, Boaretto E. 2015a. Radiocarbon dating shows an early appearance of Philistine Material Culture in Tell es-Safi/Gath, Philistia. Radiocarbon 57(5):825-50.

Asscher Y, Lehmann G, Rosen SA, Weiner S, Boaretto E. 2015b. Absolute dating of the Late Bronze to Iron Age Transition and the appearance of Philistine culture in Qubur el-Walaydah, southern Levant. Radiocarbon 57 (1):77-97.

Finkelstein I. 2016. To date or not to date: radiocarbon and the arrival the Philistines. Ägyten und Levante (Egypt and Levant) 26:275-84.

Killebrew AE. 2013. Early Philistine pottery technology at Tel Miqne-Ekron: implications for the Late Bronze-Early Iron Age transition in the eastern Mediterranean. In: Killebrew AE, Lehmann G, editors. The Philistines and Other "Sea Peoples" in Text and Archaeology. Atlanta: Society of Biblical Literature. p 77-129.

Maeir AM, Hitchcock LA. 2017. The appearance, formation and transformation of Philistine culture: new perspectives and new finds. In: Fischer P, Bürge T, editors. The Sea Peoples Up-to-Date: New Research on the Migration of Peoples in the 12th Century BCE. Vienna: Austrian Academy of Sciences. p 149-62.

Toffolo MB, Maeir AM, Chadwick JR, Boaretto E. 2012. Characterization of contexts for radiocarbon dating: results from the Early Iron Age at Tell es-Safi/Gath, Israel. Radiocarbon 54 (3-4):371-90.

Toffolo MB, Arie E, Martin MAS, Boaretto E, Finkelstein I. 2014. The absolute chronology of Megiddo, Israel in the Late Bronze and Iron Ages: high-resolution radiocarbon dating. Radiocarbon 56(1):221-44. 